\title{
The effect of phosphonate on the acid-soluble phosphorus components in the genus Phytophthora
}

\author{
J. O. Niere, ${ }^{1}$ G. DeAngelis ${ }^{1}$ and B. R. Grant ${ }^{2}$ \\ Author for correspondence: J. O. Niere. Tel: +613468 2484. Fax: +6134673089. \\ e-mail : jniere $@$ pitvax.phillip.edu.au
}

\footnotetext{
1 Department of Applied Chemistry, RMIT, Bundoora, Victoria 3083, Australia

2 Russell Grimwade School of Biochemistry, University of Melbourne, Parkville, Victoria 3052, Australia
}

\begin{abstract}
The high concentrations of short-chain soluble polyphosphates, previously reported in Phytophthora palmivora, have been found in six other species of Phytophthora, and appear to be characteristic of this genus. The distribution of phosphorus among the various acid-soluble pools was similar in all species except $P$. infestans, which accumulated less polyphosphate than other species when grown in high phosphate medium, and contained several unique and as yet unidentified organic phosphorus compounds. When grown in the presence

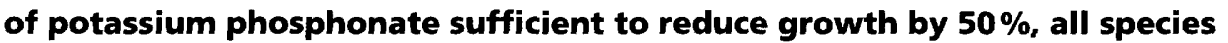
showed an increased accumulation of phosphorus in both pyrophosphate and polyphosphate, without parallel increases in sugar phosphate or nucleotide phosphorus pools. The internal concentration of phosphonate required to produce $50 \%$ inhibition varied with species, ranging from 4.6 to $52 \mu \mathrm{mol}$ (g dry wt) ${ }^{-1}$. Assimilation of orthophosphate was only slightly reduced in the presence of phosphonate, resulting in an increased concentration of phosphorus per unit mass. Metalaxyl, which also inhibits growth of Phytophthora spp. did not cause accumulation of either pyro- or polyphosphate. Phosphonate treatment also resulted in the formation of a compound identified as isohypophosphate, a metabolite of phosphonate not previously reported in Phytophthora. Taken together, these observations suggest that the primary site of phosphonate inhibition in Phytophthora spp. lies in the metabolism of pyrophosphate.
\end{abstract}

Keywords: Phytophthora spp., phosphorus assimilation, phosphonate, ${ }^{31} \mathrm{P}$ NMR

\section{INTRODUCTION}

Phosphonates, applied as either the potassium salts of phosphonic acid (Folia-R-Fos) or aluminium salts of alkyl phosphonates (Fosetyl Al, Aliette), control several diseases caused by species of pseudofungi belonging to the class Oomycetes. However, there is evidence that the spectrum of activity of phosphonate is broader and includes species from classes of organism other than Oomycetes (Chase, 1993; Davis et al., 1993; Heaton \& Dullahide, 1990). While there is strong evidence that the primary site of phosphonate action lies within the pathogen and not the host (Fenn \& Coffey, 1984), this site has not been identified.

Abbreviations: polyP, polyphosphate; pyroP, pyrophosphate; LPR, lowphosphate Ribeiro medium; NDPG, nucleoside diphosphate glucose; PCA perchloric acid; IHP, isohypophosphate.
Relatively high concentrations $(0 \cdot 1-3 \mathrm{mM})$ of phosphonates are required to reduce growth of target organisms in culture, although the anion appears to be effective in the plant at lower concentrations (Smillie et al., 1989). There is indirect evidence suggesting that phosphonates alter the wall structure of Pbytophthora spp. (Dercks \& Buchenauer, 1987; Dunstan et al., 1990; Guest, 1986). Such changes could affect the interaction between host and parasite, enhancing the activity of the host plant's dynamic defence response as observed in the presence of phosphonates (Afek \& Sztejnberg, 1989; Bompeix et al., 1980; Nemostothy \& Guest, 1990). However, it is not known whether the primary site of phosphonate action is restricted to the metabolic pathway leading to cell wall formation, or whether the effect on wall formation is secondary, resulting from a phosphonate-induced alteration in metabolism at another site. 

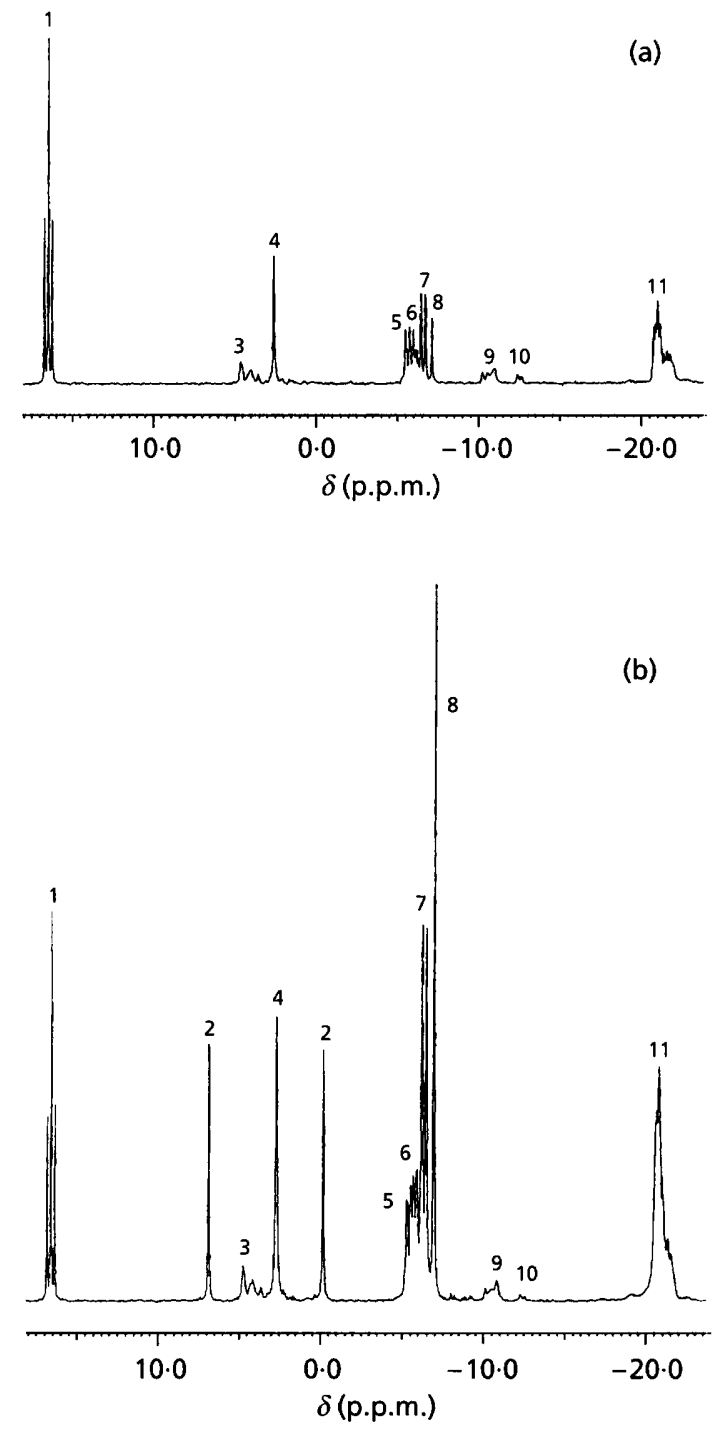

Fig. 1. ${ }^{31} \mathrm{P}$ NMR spectra at $81 \mathrm{MHz}$ of PCA extracts of $P$. citricola (a) grown in LPR and (b) grown in LPR in the presence of $0.3 \mathrm{mM}$ phosphonate. Peak assignments: 1, methylene diphosphonic acid (external standard); 2, phosphonate; 3, phosphomonoesters, e.g. fructose 6-phosphate, glycerophosphate etc, individual resonances were not assigned; 4, inorganic phosphate; 5 , terminal $P$ of polyphosphates with $>4 \mathrm{P} ; 6$, terminal $\mathrm{P}$ of tetrapolyP and $\gamma-\mathrm{P}$ of nucleoside triphosphates such as ATP; 7, terminal P of tripolyP; 8 , pyroP; 9 , $\alpha-P$ of ATP and other nucleoside tri- and diphosphates, $P$ of UDPG, and perhaps P of NAD; 10 , P of UDPG; 11 , nonterminal P of inorganic polyP and $\beta$-P of nucleoside triphosphates.

Alterations in levels of nucleotides and pyrophosphate (Griffith et al., 1990) were observed in mycelium of $P$. palmivora P113 grown on phosphonate and changes in nucleotide levels were also observed in $P$. citropithora (Barchietto et al., 1992) indicating that phosphonate causes significant perturbations in phosphorus metabolism. In this paper, the effects of phosphonate on the levels of acidsoluble phosphorylated metabolites in a number of species of Phytophthora are reported.

\section{METHODS}

Reproducibility. All data presented in this paper are representative and are based on at least three experiments except where indicated. Where data points are reported as being significantly different, the test was made by Student's $t$-test.

Strains. The following cultures originated from the Pbytophthora culture collection at the University of California, Riverside, and were obtained from Professor Michael Coffey: Phytophtbora palmivora P113 (deposited as ATCC 26286, Tokunaga \& Bartnicki-Garcia, 1971), an isolate resistant to phosphonate; $P$. palmivora $\mathrm{P} 376$, an isolate particularly sensitive to phosphonate (Dolan \& Coffey, 1988); P. citricola, P1946; P. melonis, P3239; and P. mirabilis, P3010. Phytopbthora nicotianae M3049 was isolated from tobacco (Smillie et al., 1989), while P. infestans 88198 is a metalaxyl-sensitive potato isolate obtained from the Netherlands (Grant et al., 1992).

Media and growth conditions. All cultures except $P$. infestans and $P$. mirabilis were maintained on V-8 agar and transferred to low phosphate Ribeiro agar medium (Griffith et al., 1989) prior to use as inocula in these experiments. Phytophthora infestans and $P$. mirabilis were maintained on rye seed infusion agar and grown in rye seed infusion broth (Caten \& Jinks, 1968). Other species were grown in liquid Ribeiro medium (LPR) containing $0.1 \mathrm{mM}$ phosphate, buffered with $50 \mathrm{mM}$ MES buffer adjusted to $\mathrm{pH} 6.2$ with $\mathrm{KOH}$ (Griffith et al., 1989). Thiamin and, where indicated, potassium phosphonate or metalaxyl were added aseptically after autoclaving.

Cultures were routinely grown in darkness at $26^{\circ} \mathrm{C}$ for 6 or $7 \mathrm{~d}$, which corresponded to the transition from exponential to stationary growth phase. At that time phosphate was almost exhausted in the LPR growth medium. Other growth periods were used where indicated. $P$. infestans was normally grown at $20^{\circ} \mathrm{C}$, its optimum temperature.

The level of phosphonate used was chosen to yield approximately $50 \%$ inhibition at the phosphate level supplied. In practice the inhibition obtained varied from $51-65 \%$. The specific level of phosphonate applied to each species except $P$. infestans is specified in Table 1 . The $\mathrm{EC}_{50}$ level for P. infestans 88198 grown on rye seed infusion broth was $2 \mathrm{mM}$.

Harvesting and extraction procedures. Harvesting and extraction of mycelia were carried out as described by Niere $e t$ al. (1990) with the exception that the freeze-thaw step was omitted. This change did not affect the ${ }^{31}$ P NMR spectra of the extracts obtained.

NMR preparation, conditions and calculations. Freeze-dried PCA extract was dissolved in ${ }^{2} \mathrm{H}_{2} \mathrm{O}(0.5 \mathrm{ml}), 0 \cdot 1 \mathrm{M}$ EDTA $(0.5 \mathrm{ml}, \mathrm{pH} 7.5)$ and water $(0.5 \mathrm{ml})$. The resulting solution was placed in a $10 \mathrm{~mm}$ o.d. NMR tube and the $\mathrm{pH}$ adjusted to $7 \cdot 8$ with $0.1 \mathrm{M} \mathrm{KOH}$. The final volume of the sample was adjusted to $2 \cdot 20 \pm 0.05 \mathrm{ml}$. All ${ }^{31} \mathrm{P}$ NMR experiments were conducted using a Bruker AC200-F instrument (operating frequency $81 \mathrm{MHz}$ ) at a temperature of $295 \pm 1 \mathrm{~K}$. Spectra were normally accumulated using $45^{\circ}$ pulses and $7 \mathrm{~s}$ cycle times in order to ensure total relaxation of all ${ }^{31} \mathrm{P}$ nuclei. The spectral width of $6000 \mathrm{~Hz}$ was represented by $8 \mathrm{~K}$ data points. Spectra were normally run fully coupled.

Chemical shifts were referenced to a methylene diphosphonic acid $(0.1 \mathrm{M}$ in a $1 \mathrm{~mm}$ concentric capillary tube) signal set at 16.85 p.p.m. downfield from $85 \%(\mathrm{v} / \mathrm{v}) \mathrm{H}_{3} \mathrm{PO}_{4}$. The same reference sample was used as a standard to calculate absolute concentrations of different types of phosphorus in the NMR sample. These concentrations, the NMR sample volume and 
Table 1. Acid-soluble phosphorus pools in mycelium of Phytophthora spp. in the absence or presence of sub-toxic levels of phosphonate

Results are expressed as (a) $\mu \mathrm{mol}$ phosphorus ( $\mathrm{g}$ mycelial dry $\mathrm{wt})^{-1}$ and (b) $\%$ of total acid-soluble phosphorus. Standard deviations are shown in parentheses.

\begin{tabular}{|c|c|c|c|c|c|c|c|c|c|c|c|c|c|c|c|c|c|}
\hline \multirow[t]{2}{*}{ Species } & \multirow{2}{*}{$\begin{array}{l}\text { Days } \\
\text { growth }\end{array}$} & \multirow{2}{*}{$\begin{array}{l}\text { Mean } \\
\text { polyP } \\
\text { chain } \\
\text { length }\end{array}$} & \multicolumn{3}{|c|}{ PolyP } & \multicolumn{2}{|c|}{ PyroP } & \multicolumn{3}{|c|}{$\mathbf{P}_{\mathrm{i}}$} & \multicolumn{2}{|c|}{ Nucleotide $P$} & \multicolumn{2}{|c|}{ Sugar phosphate } & \multirow{2}{*}{$\frac{\text { Total P }}{\mathbf{a}}$} & \multirow{2}{*}{$\frac{\text { Phosphonate }}{a}$} & \multirow{2}{*}{$\begin{array}{c}\text { External } \\
\text { phos- } \\
\text { phonate } \\
(\mathrm{mM})\end{array}$} \\
\hline & & & a & & $\mathrm{b}$ & $\mathbf{a}$ & b & 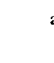 & a & b & $\mathbf{a}$ & b & a & b & & & \\
\hline P. citricola (contruli & 6 & $50(0 \cdot 3)$ & $41 \cdot 2$ & $(7.7)$ & $54(7)$ & $2 \cdot 6(1 \cdot 2)$ & $3.5(0.6)$ & $9 \cdot 3$ & $(1 \cdot 1)$ & $12(1)$ & $9 \cdot 3(1 \cdot 1)$ & $12(2)$ & $8.5(1.6)$ & $11(2)$ & $76.9(10 \cdot 4)$ & & \\
\hline P. citricola (treated) & 6 & $4 \cdot 0(0 \cdot 3)$ & $149 \cdot 6$ & $(20)$ & $67(1)$ & $24 \cdot 2(7 \cdot 7)$ & $11(3)$ & $23 \cdot 5$ & $(1 \cdot 0)$ & $9(1)$ & $10.9(3 \cdot 5)$ & $5(2)$ & $13 \cdot 5(4 \cdot 0)$ & $6(2)$ & $223 \cdot 7 \quad(0.5)$ & $23 \cdot 5 \quad(1 \cdot 5)$ & $0 \cdot 3$ \\
\hline P. melonis (contru): & 7 & $5 \cdot 2(0.3)$ & $24 \cdot 0$ & $(8 \cdot 3)$ & $44(9)$ & $1.9(0 \cdot 7)$ & $3 \cdot 8(2 \cdot 0)$ & $9 \cdot 0$ & $(2 \cdot 8)$ & $18(8)$ & $6-8(1 \cdot 7)$ & $13(1)$ & $7.6(0.7)$ & $15(1)$ & $52 \cdot 7 \quad(8 \cdot 3)$ & & \\
\hline P. melonis (treatedi) & 7 & $4 \cdot 3(0 \cdot 1)$ & $85 \cdot 3$ & $(14 \cdot 9)$ & $63(4)$ & $11 \cdot 8(0 \cdot 8)$ & $9(2)$ & $14 \cdot 4$ & $(3 \cdot 4)$ & $11(4)$ & $7.7(1.4)$ & $6(0.5)$ & $11 \cdot 1(1.9)$ & $8(1)$ & $134 \cdot 6(15 \cdot 5)$ & $4 \cdot 6(1 \cdot 3)$ & 0.4 \\
\hline P. nicotianae (control) & 7 & $6.9(0.6)$ & $44 \cdot 4$ & $(7 \cdot 0)$ & $58(6)$ & $1 \cdot 6(0.1)$ & $1.9(0.3)$ & $10 \cdot 8$ & $(5 \cdot 0)$ & $11(4)$ & $5.5(1.4)$ & $10(3)$ & $8 \cdot 6(0.9)$ & $13(2)$ & $73 \cdot 4 \quad(2 \cdot 7)$ & & \\
\hline P. nicotianat (treatcd) & 7 & $4 \cdot 4(0 \cdot 1)$ & $134 \cdot 0$ & $(9 \cdot 6)$ & $71(4)$ & $15 \cdot 4(4 \cdot 0)$ & $8(2)$ & $14 \cdot 2$ & $(3 \cdot 4)$ & $8(2)$ & $7 \cdot 1(0 \cdot 8)$ & $4(0 \cdot 5)$ & $14 \cdot 6(0 \cdot 4)$ & $8(1)$ & $188.5 \quad(4 \cdot 5)$ & $21 \cdot 8 \quad(9 \cdot 0)$ & 0.6 \\
\hline \multicolumn{18}{|l|}{ P. palmirora } \\
\hline P113 (control) & 7 & $5.5(02)$ & $24 \cdot 9$ & $(8 \cdot 2)$ & $52(4)$ & $1.4(0.7)$ & $3 \cdot 3\langle 0 \cdot 6)$ & $3 \cdot 9$ & $(1 \cdot 8)$ & $10\langle 3\rangle$ & $5 \cdot 6(0 \cdot 7)$ & $12(2)$ & $6 \cdot 3(1 \cdot 9)$ & $13(1)$ & $46 \cdot 0(13 \cdot 0)$ & & \\
\hline P113 (treated) & 7 & $4 \cdot 0(0 \cdot 2)$ & 102.9 & $(24 \cdot 5)$ & $60(3)$ & $27 \cdot 2(0 \cdot 4)$ & $15(1)$ & $19 \cdot 6$ & $(5 \cdot 0)$ & $11(2)$ & $6.5(1 \cdot 0)$ & $4(0 \cdot 5)$ & $12 \cdot 0(2 \cdot 9)$ & $7(1)$ & $174 \cdot 1(47.9)$ & $38.8(11 \cdot 6)$ & 1 \\
\hline P376 (control) & 7 & $6.2(0.5)$ & $39 \cdot 6$ & $(9 \cdot 3)$ & $63(6)$ & $1.4(0-6)$ & $20(0 \cdot 5)$ & $7 \cdot 2$ & $(3.8)$ & $11(5)$ & $6.5(0 \cdot 8)$ & $10(1)$ & $6.9(0.6)$ & $11(2)$ & $64.9(12.5)$ & & \\
\hline P376 (treated) & 7 & $3 \cdot 6\langle(0 \cdot 1)$ & $101 \cdot 3$ & $(6 \cdot 3)$ & $49(6)$ & $40.9(6.6)$ & $20(3)$ & $35 \cdot 4$ & $(12 \cdot 6)$ & $18(3)$ & $6.7(0.8)$ & $3(0-5)$ & $16 \cdot 9(1 \cdot 3)$ & $8(0)$ & $206 \cdot 0(10 \cdot 8)$ & $51.4(10.8)$ & 0.25 \\
\hline
\end{tabular}

the dry mass of the mycelium were then used to calculate the number of moles of different types of phosphorus per gram of mycelium. Peaks were assigned by reference to published chemical shifts (Navon et al., 1979). In cases where chemical shift was dependent upon $\mathrm{pH}$ and metal ion concentration, assignment was checked by spiking the extract with authentic samples and varying the $\mathrm{pH}$.

Calculations of the mean polyP chain length are as described by Niere et al. (1990) except that the contribution from pyroP was excluded in the current calculations.

Dry weights of mycelium extracted for use in the NMR studies varied. The spectra in Figs 1, 2, 3 and 5 have been scaled so that they represent extracts from equivalent mycelial masses.

Measurement of phosphate and glucose assimilation. Phosphate assimilation was determined by growing the organisms in ${ }^{32} \mathrm{P}$-labelled phosphate (specific activity $1.5 \mathrm{MBq} \mu \mathrm{mol}^{-1}$ ) and measuring the radioactivity present in aliquots of media at daily intervals, using Cerenkov counting. At completion of the assimilation experiments (normally 5-7 d), mycelia were harvested by filtration on to Whatman $\mathrm{GF} / \mathrm{C}$ filters, washed, freeze-dried and weighed. The protocol for the measurement of glucose utilization was identical, except that $\mathrm{D}-\left[\mathrm{U}^{-14} \mathrm{C}\right]$ glucose $\left(2 \mathrm{MBq} \mathrm{mol}^{-1}\right)$ was supplied to the medium and radioactivity determined by liquid scintillation counting.

Measurement of respiration. Mycelium of $P$. palmivora was grown for $5 \mathrm{~d}$ in $\mathrm{LPR}$ at $26^{\circ} \mathrm{C}$, separated from the growth medium on coarse nylon mesh and washed with fresh, sterile LPR. The washed mycelium was then blotted dry on filter paper and transferred to two conical flasks each containing $50 \mathrm{ml}$ fresh LPR containing $5 \mathrm{mM} \mathrm{D}-\left[\mathrm{U}^{14} \mathrm{C}\right]$ glucose $\left(200 \mathrm{MBq} \mathrm{mol}^{-1}\right)$ and fitted so that $200 \mathrm{ml} \mathrm{min}^{-1}$ of filtered, water-saturated air passed through each. Each flask was placed in a water bath at $26^{\circ} \mathrm{C}$. The air stream was aspirated through $1 \mathrm{M}$ sulfuric acid and collected in scintillation vials containing $3 \mathrm{ml}$ of Soluene to absorb $\mathrm{CO}_{2}$. Vials were changed every $20 \mathrm{~min}$. Scintillation fluid was then added and the radioactivity in each determined by scintillation counting in an LKB Rackbeta 1214, with an appropriate quench correction program. After $2.5 \mathrm{~h}$, potassium phosphonate was added to one flask to bring the final concentration to $1 \mathrm{mM}$ and water added to the second flask, and the collection resumed. Experiments were continued for $15 \mathrm{~h}$, and $15-25 \%$ of the added glucose was assimilated during this period. Since replication of treatments was not possible in these experiments, each experiment was repeated four times, using separate batches of mycelium.

\section{RESULTS}

\section{NMR analysis of acid-soluble phosphorus pools in Phytophthora species}

The spectra of the acid-soluble phosphorus components in control and phosphonate-treated $P$. citricola are shown in Fig. 1. Similar patterns of peaks were observed in the spectra of all other species of Phytophthora examined which included representatives from the different groups within the genus based on morphological characteristics (Waterhouse et al., 1983). The quantitative distribution of phosphorus among the major acid-soluble pools in various species and isolates is shown in Table 1. A characteristic feature of all species was the presence of large amounts of low $(\mathrm{DP}<10)$ molecular mass polyP, and the absence of high molecular mass polyP, a feature which appears to distinguish the genus. Analysis of single extracts from $P$. cinnamomi showed a similar pattern (data not shown).

Two closely related species, $P$. infestans and P. mirabilis, did not grow well on LPR. They grew better, but still poorly, in a defined medium containing $3 \mathrm{mM} \mathrm{P} \mathrm{P}_{i}$, sterol and lecithin (Hohl, 1975) and in this medium had lower polyP pool sizes than observed in other species grown on LPR $\left(0.1 \mathrm{mM} \mathrm{P}_{\mathrm{i}}\right)$. The polyP pool in $P$. infestans was smaller than in any other species examined. In the sugar phosphate region, a new peak appeared at 5.5 p.p.m. and the relative intensity of the peak at $5 \cdot 0$ p.p.m. was greater than that previously observed in other species. Neither of these peaks was assigned, the chemical shift of the latter being close to but not identical with those of glucose 6-phosphate (Fig. 2). 


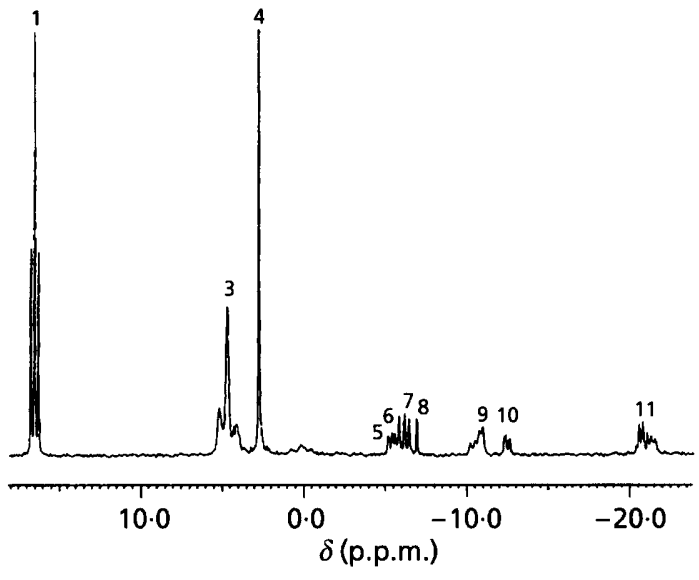

Fig. 2. ${ }^{31} \mathrm{P}$ NMR spectrum of PCA extract of $P$. infestans 88198 grown in enriched Ribeiro medium ( $P_{i}$ concn $\left.3 \mathrm{mM}\right)$. Peak assignments are as in Fig. 1.

More vigorous growth of $P$. infestans and $P$. mirabilis on rye broth $\left(0.25 \mathrm{mM} \mathrm{P}_{\mathrm{i}}\right)$ gave mycelia with a phosphorus distribution similar to that of other species grown on LPR $\left(0 \cdot 1 \mathrm{mM} \mathrm{P} \mathrm{P}_{\mathrm{i}}\right.$ ) (Fig. 3a) but without the chain-lengthening or increased accumulation of polyP observed when other species were grown in rye (Fig. 3b) or other media with phosphate levels greater than $0 \cdot 1 \mathrm{mM}$ (Niere et al., 1990).

\section{Effect of phosphonate on the distribution of acid- soluble phosphorus}

In all species and isolates examined, phosphonate-induced growth inhibition resulted in several striking changes in acid-soluble phosphorus pools (Tables 1 and 2, Fig. 1b). There was both a very large increase in the amount of acid-soluble phosphorus per unit mass of mycelium and a change in the distribution of phosphorus between the various pools. PolyP increased three- to fivefold, with concentrations reaching $85-150 \mu \mathrm{mol}$ (g dry wt mycelium $)^{-1}$. The increases in the pyroP pools were even more striking, showing 7-35-fold increases [12-41 $\mu \mathrm{rnol}$

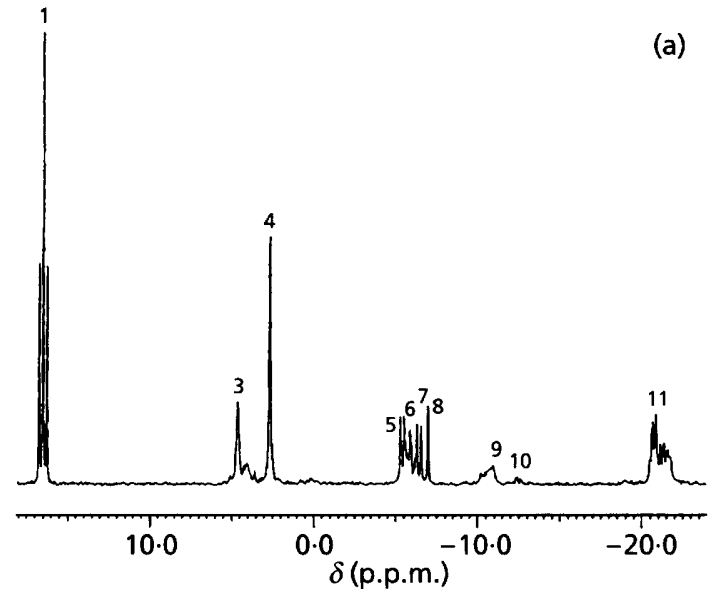

(b)

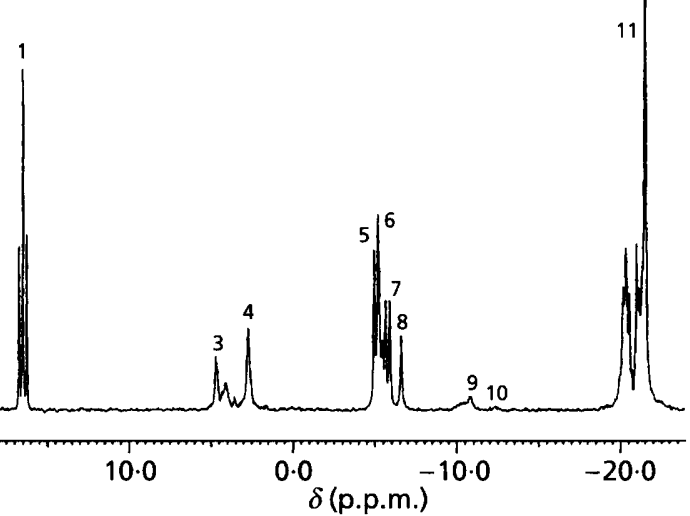

Fig. 3. ${ }^{31} \mathrm{P}$ NMR spectra of PCA extracts of (a) P. infestans 88198 , (b) $P$. palmivora $\mathrm{P} 113$ grown in rye seed infusion broth. Peak assignments are as in Fig. 1.

(g dry wt mycelium $)^{-1}$ ]. There were smaller increases in the sugar phosphate pools (up to twofold), but only little or no increase in nucleotide phosphorus. The

Table 2. Percentage changes in phosphorus pools of Phytophthora spp. treated with phosphonate

Standard deviations are shown in parentheses.

\begin{tabular}{|c|c|c|c|c|c|c|c|c|c|}
\hline Species & $\begin{array}{c}\text { Days } \\
\text { growth }\end{array}$ & $\begin{array}{l}\text { Mean } \\
\text { polyP } \\
\text { chain } \\
\text { length }\end{array}$ & PolyP & PyroP & $\mathbf{P}_{\mathrm{i}}$ & $\begin{array}{c}\text { Nucleotide } \\
\mathbf{P}\end{array}$ & $\begin{array}{c}\text { Sugar } \\
\text { phosphate }\end{array}$ & Total P & $\begin{array}{c}\text { Growth } \\
\text { inhibition } \\
(\%)\end{array}$ \\
\hline P. citricola & 6 & $-12(1)$ & $252 \quad(9)$ & $785 \quad(200)$ & $113 \quad(47)$ & $14(3)$ & $64 \quad(9)$ & $173(26)$ & $53(12)$ \\
\hline P. melonis & 7 & $-18(3)$ & $293(60)$ & $600 \quad(180)$ & 73 (56) & $15(9)$ & $46(12)$ & $157(12)$ & $65(10)$ \\
\hline P. nicotianae & 7 & $-40(5)$ & $231(40)$ & $851 \quad(200)$ & $49 \quad(38)$ & $35(19)$ & $70(12)$ & 157 (4) & $52 \quad(3)$ \\
\hline \multicolumn{10}{|l|}{ P. palmivora } \\
\hline P113 & 7 & $-27(5)$ & $415(60)$ & $2008 \quad(534)$ & $403(157)$ & $16(5)$ & $98(37)$ & $281(34)$ & $51 \quad(6)$ \\
\hline P376 & 7 & $-42(4)$ & $258(50)$ & 3417 (1363) & $639(511)$ & $5(11)$ & $146(25)$ & $224(37)$ & $58 \quad(6)$ \\
\hline
\end{tabular}


Table 3. Amount of phosphorus in different acid-soluble pools in P. palmivora P113

P. palmivora P113 was grown for 3, 5, 7 and $10 \mathrm{~d}$ in LPR alone or in LPR containing $1 \mathrm{mM}$ phosphonate. The results are expressed as $\mu \mathrm{mol} \mathrm{P}$ (gr mycelial dry wt $)^{-1}$.

\begin{tabular}{|c|c|c|c|c|c|c|c|c|c|c|}
\hline $\begin{array}{c}\text { Days } \\
\text { growth }\end{array}$ & $\begin{array}{c}1 \mathrm{mM} \\
\text { phos- } \\
\text { phonate }\end{array}$ & $\begin{array}{c}\text { Mean } \\
\text { polyP } \\
\text { chain } \\
\text { length }\end{array}$ & PolyP & PyroP & $\mathbf{P}_{\mathrm{i}}$ & $\begin{array}{c}\text { Nucleotide } \\
\text { P }\end{array}$ & $\begin{array}{c}\text { Sugar } \\
\text { phosphate }\end{array}$ & $\begin{array}{c}\text { Total } \\
\text { acid- } \\
\text { soluble } \\
\text { P }\end{array}$ & $\begin{array}{l}\text { Phos- } \\
\text { phonate }\end{array}$ & $\begin{array}{c}\text { Growth } \\
\text { inhibition } \\
(\%)\end{array}$ \\
\hline \multirow[t]{2}{*}{3} & - & $4 \cdot 8$ & 143.5 & $5 \cdot 7$ & $16 \cdot 3$ & $18 \cdot 2$ & $16 \cdot 3$ & $205 \cdot 7$ & - & \\
\hline & + & $3 \cdot 7$ & $135 \cdot 1$ & $17 \cdot 6$ & $23 \cdot 2$ & $12 \cdot 1$ & $21 \cdot 3$ & $213 \cdot 0$ & $10 \cdot 4$ & 47 \\
\hline \multirow[t]{2}{*}{5} & - & $5 \cdot 5$ & $46 \cdot 7$ & $1 \cdot 6$ & $5 \cdot 3$ & $8 \cdot 5$ & $7 \cdot 8$ & $73 \cdot 0$ & - & \\
\hline & + & $4 \cdot 3$ & $126 \cdot 9$ & $16 \cdot 2$ & $17 \cdot 6$ & $11 \cdot 4$ & $15 \cdot 3$ & $190 \cdot 0$ & $31 \cdot 2$ & 46 \\
\hline \multirow[t]{2}{*}{7} & - & $5 \cdot 2$ & $24 \cdot 2$ & $1 \cdot 0$ & $4 \cdot 3$ & $5 \cdot 7$ & $5 \cdot 4$ & $42 \cdot 2$ & - & \\
\hline & + & $4 \cdot 3$ & $92 \cdot 3$ & $18 \cdot 7$ & $12 \cdot 8$ & $7 \cdot 0$ & $8 \cdot 8$ & $143 \cdot 0$ & $30 \cdot 2$ & 53 \\
\hline \multirow[t]{2}{*}{10} & - & 4.9 & $19 \cdot 0$ & $1 \cdot 0$ & $2 \cdot 4$ & $4 \cdot 0$ & $3 \cdot 3$ & $31 \cdot 0$ & - & \\
\hline & + & $3 \cdot 8$ & $101 \cdot 6$ & $30 \cdot 2$ & $17 \cdot 7$ & $6 \cdot 1$ & $12 \cdot 7$ & $175 \cdot 0$ & $38 \cdot 8$ & 64 \\
\hline
\end{tabular}

orthophosphate pool also increased with the $P$. palmivora isolates (P113 and P376) showing the largest changes.

Fully coupled ${ }^{31} \mathrm{P}$ NMR spectra of PCA extracts of phosphonate-treated mycelia (Fig. 1b) contained a small doublet $(J 17 \mathrm{~Hz})$ at $-7 \cdot 8$ p.p.m. which does not appear to have been reported previously in any ${ }^{31} \mathrm{P}$ NMR spectra of biological extracts. In proton-decoupled spectra this doublet was replaced by a more intense doublet $(J 17 \mathrm{~Hz})$ at -3.8 p.p.m. This suggested that the doublet arose from a ${ }^{31} \mathrm{P}$ nucleus coupled to both an $\mathrm{H}(J$ approx. $640 \mathrm{~Hz})$ and to another $\mathrm{P}(J 17 \mathrm{~Hz})$. The simplest molecule incorporating this arrangement is isohypophosphate (IHP):<smiles>O=[PH]([O-])OP(=O)([O-])[O-]</smiles>

The observed chemical shifts and coupling constants are consistent with those previously reported for IHP (Van Wazer, 1958). The fully coupled spectrum of the IHP anion consists of a doublet of doublets (phosphonate $P$, centred at -1 p.p.m.) and a doublet (phosphate P, centred at -3 p.p.m.). In the fully coupled spectrum of the mycelial extract, the phosphate signal of IHP would be obscured by the low-field terminal polyP peaks, while the doublet comprising the low-field half of the IHP phosphonate signal would be obscured by the high-field half of the very large phosphonate doublet at $0 \cdot 0$ p.p.m. To confirm the identity of the phosphorylated metabolite, $\mathrm{X}$, a mixture of IHP, pyroP, phosphonate and phosphate was prepared as described by Blaser \& Worms (1959). The mycelial acid-extract was fractionated through a Dowex $1 \times 8$-formate anion exchange column and a fraction consisting of $\mathrm{X}$, pyroP, phosphonate and phosphate (as indicated by ${ }^{31} \mathrm{P}$ NMR) was isolated, neutralized and freeze-dried. Proton and ${ }^{13} \mathrm{C}$ NMR spectra of this fraction indicated that the only organic material present was residual formic acid. ${ }^{31} \mathrm{P}$ NMR spiking experiments of this fraction with the synthetic mixture containing IHP confirmed that $\mathrm{X}$ was isohypophosphate. Isohypophosphate was never observed in mycelial extracts which had not been exposed to phosphonate. There were no IHP peaks in the NMR spectrum of the original phosphonate stock.

In those cases where internal levels of phosphonate were very low ( $P$. melonis and $P$. infestans), no IHP peaks were detectable. In order to determine whether this compound was simply an artifact formed by reaction of phosphonate with phosphate or pyrophosphate during the extraction procedure, mixtures of phosphonate with the growth medium and phosphonate with pyrophosphate were subjected to the same freeze-drying and extraction procedures as the phosphonate-treated mycelia. No isohypophosphate peaks could be found in the ${ }^{31} \mathrm{P}$ NMR spectra of the resulting mixtures.

\section{Variation in size of internal phosphonate pools}

Internal phosphonate pool sizes ranged from 4.6-51.4 $\mu \mathrm{mol}(\mathrm{g} \text { dry } \mathrm{wt})^{-1}$. There was no consistent relationship between the internal pool sizes and the concentration of phosphonate supplied. For example, the phosphonate pool sizes in P. palmivora P113 and P376 were similar, despite a fourfold difference in external phosphonate concentrations. Phosphonate pool sizes in $P$. nicotianae and $P$. citricola were approximately half those observed in the P. palmivora isolates, and the pool size in $P$. melonis was very much smaller than in any other isolates examined. Although this may be due in part to $P$. melonis containing less soluble material $(g \text { dry } w t)^{-1}$ than the other species, the amount of phosphonate measured as a fraction of total acid-soluble phosphorus was still only half that observed for $P$. nicotianae and $P$. citricola. These observations support the conclusions of Griffith et al. (1993) who not only found differences between isolates in their capacity to exclude phosphonate at the level of the 

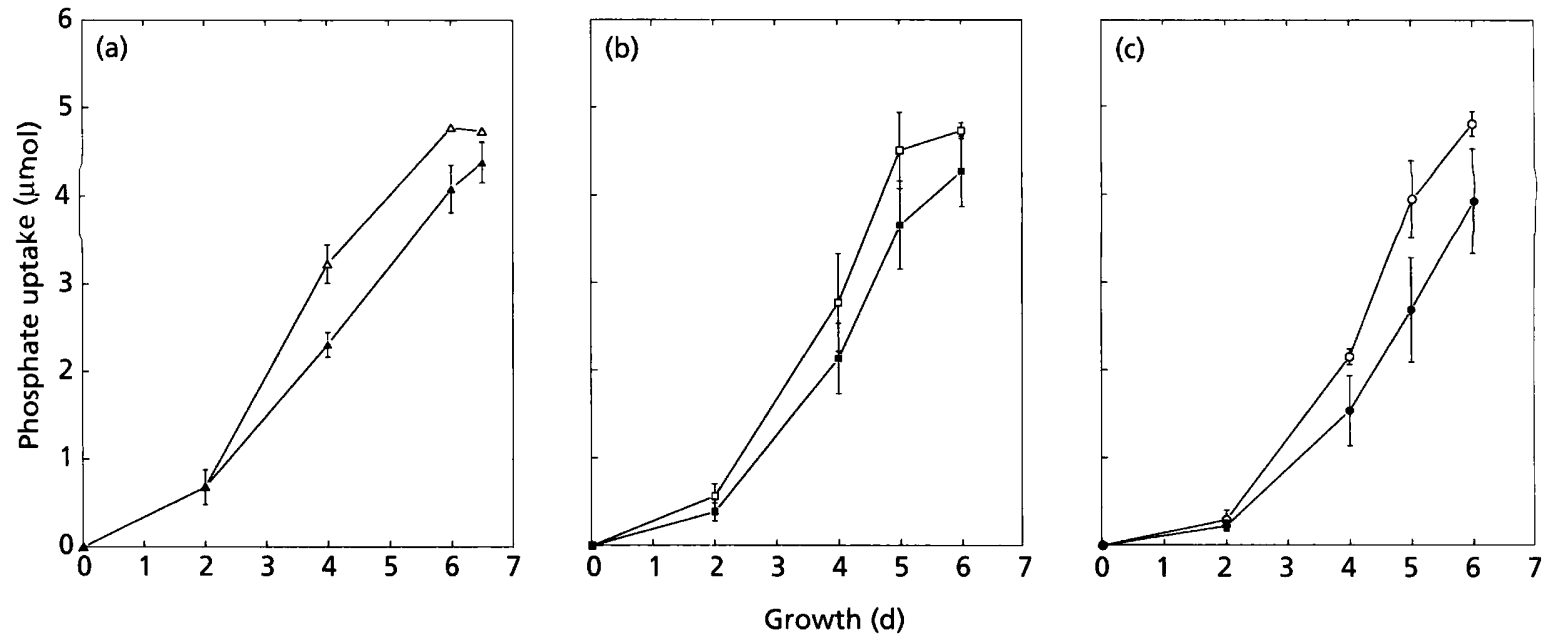

Fig. 4. Phosphate uptake in the absence (open symbols) or presence (filled symbols) of phosphonate [1 $\mathrm{mM}$ (a), $0.3 \mathrm{mM}$ (b, c)]: (a) P. palmivora P113; (b) P. palmivora P376; (c) P. citricola.

phosphate-phosphonate translocator, but also differences between isolates in their sensitivity to internal phosphonate pools of similar magnitude.

When $P$. infestans was grown on rye broth in the presence of phosphonate, the amount of phosphonate accumulated $\left[14.4 \mu \mathrm{mol}\left(\mathrm{g} \mathrm{dry} \mathrm{wt}^{-1}\right]\right.$ was smaller than in other species inhibited to a comparable extent although similar increases in pyroP and polyP were observed.

\section{Effect of culture age on phosphorus distribution}

A single set of analyses made on P. palmivora P113 harvested after 3, 5, 7 and $10 \mathrm{~d}$ growth in LPR showed the effect of culture age on the distribution of phosphorus between the various pools (Table 3 ). Under the conditions of the experiment, $60 \%$ of external $\mathrm{P}_{i}$ was assimilated by day 3 and more than $90 \%$ by day 5 (see Fig. 4a), although the mycelial mass continued to increase until day 10 . As a consequence, there was a significant fall in the total acidsoluble phosphorus expressed on a dry weight basis as the culture aged, with the maximum change occurring between days 3 and 5 . There was only a small shift in distribution of phosphorus from acid-soluble inorganic to organic pools over this period, with $81 \%$ of acid-soluble phosphorus in the inorganic pool at day $3,73 \%$ at day 5 and $71 \%$ at day 10 . These results are not consistent with the hypothesis that polyP functions as a phosphorus reserve in this genus. In a separate experiment, mycelium grown for $10 \mathrm{~d}$ under these conditions, washed and then transferred to new medium from which $\mathrm{P}_{\mathrm{i}}$ was omitted, failed to increase in mass. This suggests that the accumulation of polyP is not a function of culture age, and that once accumulated, polyP cannot be utilized as an internal source of phosphorus when external sources are depleted.

The presence of phosphonate had two effects. The first was that the total pool size of acid-soluble phosphorus
Table 4. Effect of phosphonate on phosphate assimilation by Phytophthora spp.

\begin{tabular}{|lcc|}
\hline Species & $\begin{array}{c}\text { Phosphonate } \\
(\mathbf{m M})\end{array}$ & $\begin{array}{c}\text { Phosphate } \\
\text { assimilated } \\
\left(\boldsymbol{\mu} \mathbf{m o l} \mathbf{~ g}^{-1}\right)\end{array}$ \\
\hline P. palmivora P113 & 0 & 196 \\
& $1 \cdot 0$ & 285 \\
P. palmivora P376 & 0 & 328 \\
& $0 \cdot 3$ & 544 \\
P. palmivora P7228 & 0 & 351 \\
& $0 \cdot 3$ & 453 \\
P. citricola & $1 \cdot 0$ & 363 \\
& 0 & 200 \\
& $0 \cdot 3$ & 428 \\
\hline
\end{tabular}

was much higher at all times and that this was particularly apparent after day 3 (Table 3 ). The second was that the relative increase in the pyroP pool was observed even at day 3 , well before growth became $\mathrm{P}_{\mathrm{i}}$ limited, and before the relative increases in poly $\mathrm{P}$ became apparent.

\section{Phosphate assimilation}

The accumulation of more acid-soluble phosphate ( $\mathrm{g}$ dry $\mathrm{wt})^{-1}$ in the presence of phosphonate than in untreated mycelia (Table 4) was shown to result from a differential effect of phosphonate on the rate of $P_{i}$ assimilation and growth. Phosphonate did reduce the rate of $\mathrm{P}_{\mathrm{i}}$ assimilation, and the limiting concentration, $4 \mu \mathrm{M}$, was reached $24 \mathrm{~h}$ later than in control cultures (Fig. 4). However, the reduction in growth in the phosphonate-treated cultures was much greater than the reduction in $\mathrm{P}_{\mathrm{i}}$ assimilation, resulting in higher total phosphorus $(\mathrm{g} \text { dry wt })^{-1}$. 
Table 5. Effect on metalaxyl on phosphate uptake by Phytophthora palmivora P113

\begin{tabular}{|c|c|c|c|}
\hline & $\begin{array}{c}\text { Mycelial } \\
\text { mass } \\
(\mathrm{mg})\end{array}$ & $\begin{array}{c}\text { Phosphate } \\
\text { ( } \mu \mathrm{mol})\end{array}$ & $\begin{array}{l}\text { Phosphate } \\
\text { assimilated } \\
\left.(\mu \mathrm{mol} \mathrm{g})^{-1}\right)\end{array}$ \\
\hline Control & $22 \cdot 3 \pm 1 \cdot 6$ & $4 \cdot 7 \pm 0 \cdot 1$ & 200 \\
\hline Metalaxyl $0 \cdot 05 \mathrm{mg} \mathrm{I}^{-1}$ & $12 \cdot 1 \pm 1 \cdot 7$ & $3 \cdot 5 \pm 0 \cdot 3$ & 300 \\
\hline Metalaxyl $0 \cdot 1 \mathrm{mg} \mathrm{l}^{-1}$ & $4 \cdot 0 \pm 1 \cdot 8$ & $1 \cdot 5 \pm 0.4$ & 300 \\
\hline
\end{tabular}

\section{Effect of metalaxyl}

To test whether these effects of phosphonate were specific, or the result of general inhibition of growth, the effect of sub-toxic concentrations of metalaxyl, an acylalanine fungicide (Schwinn \& Staub, 1987) was examined using P. palmivora P113. Metalaxyl is considered to act at the level of RNA polymerase (Davidse \& Van denBerg Velthius, 1989) and isolates of Phytophthora resistant to metalaxyl do not show cross-resistance to phosphonate (Bower \& Coffey, 1985), suggesting that the two fungicides do not share a common site of action.

When P. palmivora P113 was grown in the presence of metalaxyl $\left(0.05\right.$ and $\left.0 \cdot 1 \mu \mathrm{g} \mathrm{ml}^{-1}\right)$, growth was inhibited $50 \%$ and $80 \%$ respectively (Table 5). The effect on $P_{i}$ assimilation was comparable to that observed when phosphonate inhibited growth, suggesting that this was not a specific effect. However, PCA extracts of mycelium grown in the presence of metalaxyl showed none of the changes in pyroP and polyP characteristic of phosphonate-treated P. palmivora P113 (Fig. 5) which suggests that these are specific effects.

\section{Effect of phosphonate on glucose assimilation}

The conversion of phosphate to pyroP and poly $\mathrm{P}$ requires the expenditure of energy to form each phosphoanhydride bond. The requirement must be met either by an increase in the rate of glucose oxidation or a diversion of energy from other synthetic pathways. Growth of $P$. palmivora P113 and P376, and P. citricola in the presence of radiolabelled glucose showed no increase in glucose assimilation during growth in the presence of phosphonate (Table 6). Glucose assimilation $(\mathrm{g} \text { dry wt })^{-1}$ was reduced in proportion to the reduction in mycelial mass, except in the case of $P$. citricola where it was reduced proportionately more.

When phosphonate $(1 \mathrm{mM})$ was supplied to actively growing cultures of $P$. palmivora P376, washed and resuspended in fresh LPR an inhibition of $\mathrm{CO}_{2}$ evolution was observed within $1 \mathrm{~h}$ of addition of phosphonate (Fig. 6). Addition of phosphonate to P. palmivora P113 under identical conditions resulted in either no effect or very slight inhibition of respiration (data not shown). This difference would be predicted, since assimilation of phosphonate is more rapid into P376 than it is into P113 under the experimental conditions used (Griffith $e t$ al., 1993). We have never observed stimulation of respiration in the presence of phosphonate.
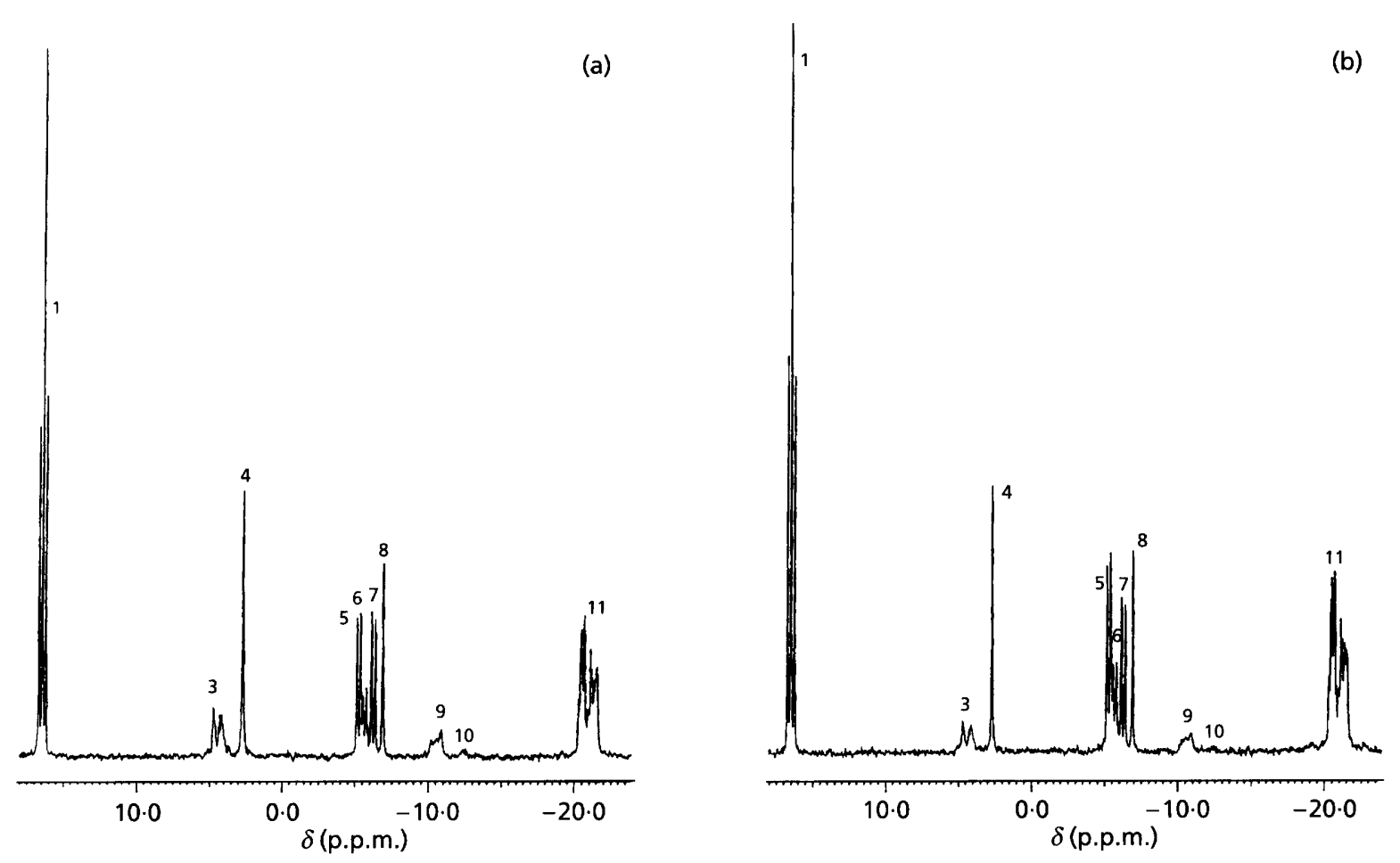

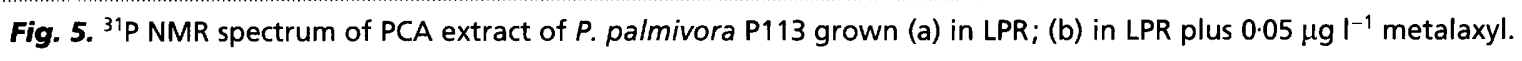


Table 6. Effect of phosphonate on consumption of glucose by Phytophthora spp.

Results are expressed as means \pm sD.

\begin{tabular}{|lcccc|}
\hline Species & $\begin{array}{c}\text { Phosphonate } \\
(\mathbf{m} \mathbf{M})\end{array}$ & $\begin{array}{c}\text { Mean glucose } \\
\text { used per flask } \\
(\boldsymbol{\mu m o l})\end{array}$ & $\begin{array}{c}\text { Mean dry } \\
\text { weight per } \\
\text { flask }(\mathbf{m g})\end{array}$ & $\begin{array}{c}\text { Glucose use } \\
\text { on a dry wt } \\
\text { basis } \\
\left(\mathbf{m m o l} \mathbf{~ g}^{-1}\right)\end{array}$ \\
\hline P. palmivora P113 & 0 & $2 \cdot 64 \pm 0 \cdot 13$ & $22 \cdot 76 \pm 0 \cdot 78$ & $0 \cdot 12 \pm 0 \cdot 01$ \\
& $1 \cdot 0$ & $1 \cdot 30^{a} \pm 0 \cdot 10$ & $12 \cdot 47^{a} \pm 0 \cdot 37$ & $0 \cdot 10 \pm 0 \cdot 01$ \\
P. palmivora P376 & 0 & $2 \cdot 23 \pm 0 \cdot 16$ & $18 \cdot 59 \pm 1 \cdot 20$ & $0 \cdot 12 \pm 0 \cdot 01$ \\
& $0 \cdot 3$ & $1 \cdot 02^{a} \pm 0 \cdot 14$ & $9 \cdot 60^{a} \pm 1 \cdot 30$ & $0 \cdot 11 \pm 0 \cdot 01$ \\
P. citricola & 0 & $2 \cdot 21 \pm 0 \cdot 20$ & $18.90 \pm 0 \cdot 73$ & $0 \cdot 12 \pm 0 \cdot 01$ \\
& $0 \cdot 3$ & $0 \cdot 44^{a} \pm 0 \cdot 12$ & $5 \cdot 00^{a} \pm 0.44$ & $0 \cdot 07^{b} \pm 0 \cdot 04$ \\
\hline
\end{tabular}

${ }^{a}$ Significantly different from control, $P<0.001 ;{ }^{b}$ significantly different from control, $P<0.01$.

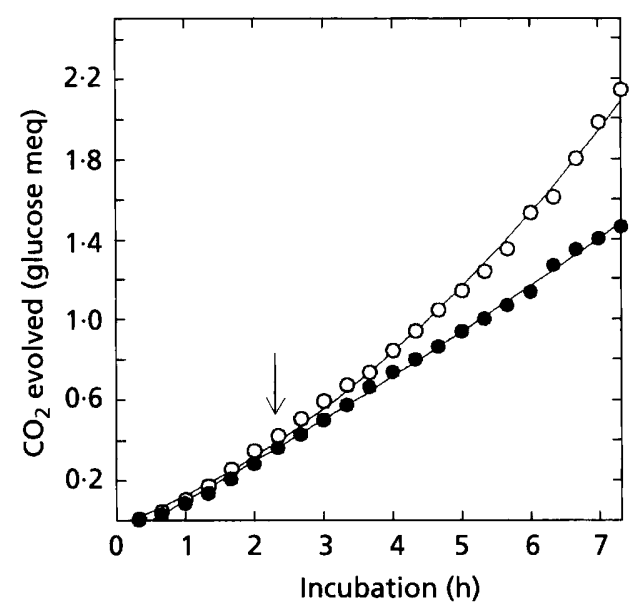

Fig. 6. Effect of phosphonate on $\mathrm{CO}_{2}$ evolution from actively growing $P$. palmivora P376. Phosphonate was added at the time indicated by the arrow. $O$, Culture with no added phosphonate; 0 , culture to which $1 \mathrm{mM}$ phosphonate was added.

\section{DISCUSSION}

Analysis of acid-soluble phosphorus compounds by ${ }^{31} \mathrm{P}$ NMR showed a high degree of similarity in the type and concentration of compounds present in all species of Phytopbthora examined, regardless of the group to which they are placed in the classification of Waterhouse $e t$ al. (1983). The exception to this observation was in the closely related (Galindo \& Hohl, 1985) $P$. infestans and $P$. mirabilis where there were differences in polyP accumulation and where other, as yet unidentified, phosphorus compounds not found in the other species were observed. It is clear from our data that the presence of short-chain poly $\mathrm{P}$ is a characteristic feature of the genus, and not in any way unique to $P$. palmivora.

When growth of Phytophthora spp. was inhibited by phosphonate, the amount of phosphate assimilated per unit mycelial mass increased. This was not a specific effect, since the same result was observed with metalaxyl inhibition. However, in the presence of phosphonate, most of the phosphate assimilated was converted to pyroP and polyP, while in the presence of metalaxyl it remained as $\mathrm{P}_{\mathrm{i}}$. The accumulation of pyroP and poly $\mathrm{P}$ therefore appears to be induced by phosphonate. This effect was evident in all species treated, regardless of their sensitivity to phosphonate.

The level of internal phosphonate which resulted in $50 \%$ inhibition of growth varied widely between the different species. The internal phosphonate pool sizes in $P$. nicotianae and $P$. citricola were only half those in $P$. palmivora and that in $P$. melonis was only $10 \%$, although the extent of growth inhibition was essentially the same. The internal concentration of phosphonate required to inhibit growth of $P$. infestans was also low $[14 \cdot 4 \mu \mathrm{mol}(\mathrm{g}$ dry wt $)^{-1}$ ] although a strict comparison with other species is not possible because of the different growth media used. There are clearly differences in sensitivity between the different species at the internal site(s) at which phosphonate acts. These are in addition to differences in capacity to exclude phosphonate when phosphate is also present (Griffith et al., 1993). Together these would determine the sensitivity to phosphonate at the whole organism level.

The increases in both pyroP and polyP induced by phosphonate must result from either an increased rate of synthesis or a decreased rate of utilization of these compounds. We know that the changes are rapid and that the increase in the pyroP pool size is one of the earliest effects observed in phosphonate-treated mycelium in $P$. palmivora P376 (J. M. Griffith, unpublished). Changes in pool size of nucleotide phosphorus are also observed in these conditions and in earlier experiments carried out over a short period under somewhat different conditions (Griffith et al., 1990).

If pyroP breakdown is inhibited in the presence of phosphonate, a likely target site is the inorganic pyrophosphatase, which is abundant in the genus (Sysuev et al., 1978) or a V-type proton translocating pyrophosphatase such as is found in the vacuolar membrane of 
plants (Rea \& Poole, 1993). To account for the parallel increase in accumulation of polyphosphate, one needs to postulate phosphonate inhibition of the polyphosphate phosphatase which hydrolyses low molecular mass polyP, and is found in this genus (Sysuev et al., 1978). However, it is possible that in these organisms, polyP is formed using pyroP as a primer although, in those few microorganisms in which poly P metabolism has been studied in detail, polyP is formed by phosphate adenyl kinase acting directly on orthophosphate (Wood \& Clarke, 1988). We presently have insufficient information about the metabolism of inorganic phosphorus to know how polyP is formed in the genus Phytophthora.

If phosphonate increases the rate of synthesis of pyroP and poly $\mathrm{P}$, the most logical site to examine is the mitochondria, where it has been demonstrated that proton-translocating pyrophosphatases exist (Griffiths \& Halestrap, 1993) and where there is some evidence for the presence of polyP accumulation, at least in yeast (Beauvoit et al., 1989). An increase in the viscosity of the inner phase of mitochondria can result in the formation of pyroP rather than ATP in some species of micro-organism (Dawes, 1986) and it has been well established that the chromatophores of Rhodospirillum rubrum contain a pyrophosphatase which utilizes the photosynthetically generated proton gradient in competition with the proton translocating ATPase (Mitchell et al., 1972; Nyren et al., 1986).

Accumulation of pyroP and polyP can be expected to have two consequences, either of which might be expected to reduce growth. Formation of pyroP and polyP from orthophosphate requires energy. This is ultimately dependent upon oxidation of the carbon source and, if growth rates are to be maintained when there is a significant diversion of energy to stored phosphoanhydride bonds, an increase in utilization of glucose (the primary carbon source) per unit mycelial mass would be required. As we have shown, there was neither an increase in glucose utilization nor an increase in respiration in the presence of phosphonate in the case of $P$. palmivora. Barchietto et al. (1992) had previously shown that phosphonate had no effect on oxygen consumption by $P$. citrophthora during the first $2 \mathrm{~h}$ of exposure, and inhibited respiration occurred after that. Increased accumulation of pyroP and poly $\mathrm{P}$ in the presence of phosphonate must therefore divert ATP from other pathways of metabolism, which can only result in a decrease in the growth rate.

The very large increases in pyroP might be expected to have a further effect, unless localized in a compartment isolated from the cellular metabolism. PyroP is formed by cleavage of nucleotide triphosphates in pyrophosphorylase reactions. These reactions occur in all major biosynthetic pathways, and the formation of UDPG from UDP and glucose 1-phosphate (Munch-Petersen et al., 1953 ) is a typical example. PyroP formed during these reactions is normally hydrolysed rapidly by inorganic pyrophosphatase, regenerating orthophosphate and assisting in the formation of the dinucleotide product by a mass action effect. If the concentration of pyroP increases, pyrophosphorylation reactions produce lower concentra- tions of their products which, like UDPG, are key intermediates in synthesis of polysaccharides, nucleic acids, lipids and proteins. Therefore a wide range of metabolic pathways essential to growth would be reduced in activity as pyroP accumulates.

It was reported (Barchietto et al., 1992) that exposure of $P$. citrophthora to phosphonate for $24 \mathrm{~h}$ resulted in a tenfold increase in the extractable activity of UDPG pyrophosphorylase. One interpretation of this result might be that the increase in the amount of enzyme present is the result of a feed-back loop, working to maintain the level of UDPG in the presence of phosphonate. We do not know whether the effect of pyroP accumulation can be compensated for in all pyrophosphorylase reactions and unless it can be, inhibition of growth must result.

Accumulation of polyP and pyroP will also be expected to alter the concentration of cations such as potassium, magnesium, calcium and iron, all of which have high affinities for pyroP and polyP. This alteration in internal ion balance might also influence the activity of a range of enzymes catalysing essential steps in metabolism.

If the explanation of phosphonate toxicity lies in its capacity to increase pyroP and thus indirectly inhibit pyrophosphorylase reactions, it remains to be explained why higher plants and animals should be so insensitive to the presence of high concentrations of phosphonate.

\section{ACKNOWLEDGEMENTS}

This work was supported in part by ARC grant AO9130971 to B.R.G. The technical assistance of Sieu Cleeland is gratefully acknowledged. Part of the data describing the effects of metalaxyl was obtained by Troy Czaja in partial fulfilment of the requirements for the B. Ag. Sc. degree.

\section{REFERENCES}

Afek, U. \& Sztejnberg, A. (1989). Effects of fosetyl-Al and phosphorous acid on scoparone, a phytoalexin associated with resistance of Citrus to Phytophthora citrophthora. Phytopathology 79, 736-739.

Barchietto, T., Saindrenan, P. \& Bompeix, G. (1992). Physiological responses of Phytopbthora citrophthora to a subinhibitory concentration of phosphonate. Pest Chem Physiol 42, 151-166.

Beauvoit, B., Rigoulet, M., Guerin, B. \& Canioni, P. (1989). Polyphosphates as a source of high energy phosphates in yeast mitochondria: a ${ }^{31} \mathrm{P}$ NMR study. FEBS Lett 252, 17-21.

Blaser, B. \& Worms, K.-H. (1959). Uber Phosphorsauren niederer Oxydationszahl. V. Z Anorg Allg Chem 301, 18-35.

Bompeix, G., Ravise, A., Raynal, G., Fettouche, F. \& Durand, M. C. (1980). Modalités de l'obtention des nécroses bloquantes sur feuilles détachées de tomate par l'action du tris-o-éthyl phosphonate d'aluminium (phoséthyl d'aluminium), hypothèses sur son mode d'action in vivo. Ann Phytopath 12, 337-351.

Bower, L. A. \& Coffey, M. D. (1985). Development of laboratory tolerance to phosphorous acid, fosetyl-Al and metalaxyl in Phytophthora capsici. Can J Plant Pathol 7, 1-6.

Caten, C. E. \& Jinks, J. L. (1968). Spontaneous variability in single isolates of Phytophthora infestans. I. Cultural variation. Can J Bot 46, 329-348. 
Chase, A. R. (1993). Efficacy of Fosetyl-Al for control of some bacterial diseases on ornamentals. Plant Dis 77, 771-776.

Davidse, L. \& Van denBerg-Velthius, G. C. M. (1989). Biochemical and molecular aspects of the phenylamide fungicide receptor interaction in plant pathogenic Phytophthora spp. In Signal Molecules in Plants and Plant-Microbe Interactions, pp. 261-266. Edited by B. J. J. Lugtenberg. Berlin: Springer-Verlag.

Davis, A. J., Say, M., Snow, A. J. \& Grant, B. R. (1993). Sensitivity of Fusarium oxysporum f.sp cubense to phosphonate. Plant Patbol 43, 200-205.

Dawes, E. A. (1986). Microbial Energetics, pp. 151-158. Glasgow: Blackie.

Dercks, W. \& Buchenauer, H. (1987). Comparative studies on the mode of action of aluminium ethyl phosphite in four Phytophthora species. Crop Prot 6, 82-89.

Dolan, T. E. \& Coffey, M. D. (1988). Correlative in vitro and in vivo behaviour of mutant strains of Phytophthora palmivora expressing different resistances to phosphorous acid and fosetyl-Na. Phytopatbology 78, 974-978.

Dunstan, R. H., Smillie, R. H. \& Grant, B. R. (1990). The effect of sub-toxic levels of phosphonate on the metabolism and virulence factors of Phytophthora palmivora. Pbysiol Mol Plant Pathol 36, 205-220.

Fenn, M. E. \& Coffey, M. D. (1984). Studies on the in vivo and in vitro antifungal activity of fosetyl-Al and phosphorous acid. Phytopatbology 74, 606-611.

Galindo, A. J. \& Hohl, H. R. (1985). Phytophthora mirabilis, a new species of Phytophthora. Sydowia 38, 87-89.

Grant, B. R., Grant, J. H. \& Harris, J. (1992). Inhibition of growth of Phytophthora infestans by phosphate and phosphonate in defined media. Exp Mycol 16, 240-244.

Griffith, J. M., Smillie, R. H., Niere, J. O. \& Grant, B. R. (1989). Effects of phosphate on the toxicity of phosphite in Phytophtbora palmivora. Arch Microbiol 152, 425-429.

Griffith, J. M., Smillie, R. H. \& Grant, B. R. (1990). Alterations in nucleotide and pyrophosphate levels in Phytopbthora palmivora following exposure to the antifungal agent potassium phosphonate (phosphite). J Gen Microbiol 136, 1285-1291.

Griffith, J. M., Coffey, M. D. \& Grant, B. R. (1993). Phosphonate inhibition as a function of phosphate concentration in isolates of Pbytophthora palmivora. J Gen Microbiol 139, 2109-2116.

Griffiths, E. J. \& Halestrap, A.P. (1993). Pyrophosphate metabolism in the perfused heart and isolated heart mitochondria and its role in regulation of mitochondrial function by calcium. Biocbem J 290, 489-495.

Guest, D. I. (1986). Evidence from light microscopy of living tissues that fosetyl-Al modifies the defence response in tobacco seedlings following inoculation with Phytophthora nicotianae var nicotianae. Physiol Mol Plant Patbol 29, 151-161.

Heaton, J. B. \& Dullahide, S. R. (1990). Efficacy of phosphonic acid in other host-pathogen systems. Aust Plant Patbol 19, 133-134.

Hohl, H. R. (1975). Levels of nutritional complexity in Pbytophthora: lipids, nitrogen sources and growth factors. Phytopathol Z 84, 18-232.

Mitchell, P., Mitchell, R. \& Moyle, J. (1972). Proton translocating pyrophosphatase of Rbodospirillum rubrum. FEBS Lett 23, 233-236.

Munch-Petersen, A., Kalckar, H. M., Cutolo, E. \& Smith, E. (1953). Uridyl transferases and the formation of uridine triphosphate. Nature 172, 1036-1037.

Navon, G., Shulman, R. G., Yamane, T., Eccleshall, T. R., Lam, K.-B., Baronofsky, J. J. \& Marmur, J. (1979). Phosphorus-31 nuclear magnetic resonance studies of wild-type and glycolytic pathway mutants of Saccharomyces cerevisiae. Biocbemistry 18, 4487-4499.

Nemostothy, G. N. \& Guest, D. I. (1990). Stimulation of phenylalanine ammonia lyase activity, ethylene biosynthesis and phytoalexin accumulation in tobacco infected with Phytophthora nicotianae following treatment with fosetyl-Al. Physiol Mol Plant Patbol 37, 207-219.

Niere, J. O., Griffith, J. M. \& Grant, B. R. (1990). ${ }^{31}$ P NMR studies on the effect of phosphite on Pbytophthora palmivora. J Gen Microbiol 136, 147-156.

Nyren, P., Nore, B. F. \& Baltscheffsky, M. (1986). Studies on photosynthetic inorganic pyrophosphate formation in Rhodospirillum rubrum chromatophores. Biochim Biophys Acta 851, 276-282.

Rea, P. A. \& Poole, R. J. (1993). Vacuolar $\mathrm{H}^{+}$-translocating pyrophosphatase. Ann Rev Plant Pbysiol Plant Mol Biol 44, 157-180.

Schwinn, F. \& Staub, T. (1987). Phenylamides and other fungicides against Oomycetes. In Modern Selective Fungicides: Properties, Applications, and Mechanisms of Action, pp. 259-274. Edited by H. Lyr. Harlow: Longman.

Smillie, R. H., Grant, B. R. \& Guest, D. I. (1989). The mode of action of phosphite: evidence for both direct and indirect modes of action on three species of Pbytopbthora in plants. Pbytopatbology 79, 921-926.

Sysuev, V. A., Konoshenko, G. I., Terekhova, V. A., Okorov, L. A., D'Yakov, Yu. T. \& Kulaev, I. S. (1978). Phosphohydrolases of the phytopathogenic fungus Phytophtbora infestans. Biokbimiya 43, 1790-1795.

Tokunaga, J. \& Bartnicki-Garcia, S. (1971). Cyst wall formation and endogenous carbohydrate utilization during synchronous encystment of Pbytopbthora palmivora zoospores. Arch Microbiol 79, 283-292.

Van Wazer, J. R. (1958). Phosphorus and Its Compounds, vol. I. New York: Interscience.

Waterhouse, G. M., Newhook, F. J. \& Stamps, D. J. (1983). Present criteria for classification of Phytophthora. In Phytophthora, Its Biology, Taxonomy, Ecology and Pathology, pp. 139-147. Edited by D. C. Erwin, S. Bartnicki-Garcia \& P. H. Tsao. St Paul, Minnesota: American Phytopathological Society.

Wood, H. G. \& Clarke, J. E. (1988). Biological aspects of inorganic polyphosphates. Annu Rev Biochem 57, 235-260.

Received 22 November 1993; revised 24 January 1994; accepted 31 January 1994. 